\title{
CALIPSO observations of transatlantic dust: vertical stratification and effect of clouds
}

\author{
W. Yang ${ }^{1,2}$, A. Marshak ${ }^{2}$, T. Várnai ${ }^{2,3}$, O. V. Kalashnikova ${ }^{4}$, and A. B. Kostinski ${ }^{5}$ \\ ${ }^{1}$ Goddard Earth Sciences Technology and Research, Universities Space Research Association, Columbia, \\ MD 21044, USA \\ ${ }^{2}$ NASA Goddard Space Flight Center, Greenbelt, MD 20771, USA \\ ${ }^{3}$ Joint Center for Earth System Technology, University of Maryland at Baltimore County, Baltimore, \\ MD 21228, USA \\ ${ }^{4}$ Jet Propulsion Laboratory, 4800 Oak Grove Drive, Ms 180-401, Pasadena, CA 91109, USA \\ ${ }^{5}$ Department of Physics, Michigan Technological University, Houghton, MI 49931, USA \\ Correspondence to: W. Yang (weidong.yang@nasa.gov)
}

Received: 16 March 2012 - Published in Atmos. Chem. Phys. Discuss.: 10 May 2012

Revised: 15 November 2012 - Accepted: 1 September 2012 - Published: 3 December 2012

\begin{abstract}
We use CALIOP nighttime measurements of lidar backscatter, color and depolarization ratios, as well as particulate retrievals during the summer of 2007 to study transatlantic dust properties downwind of Saharan sources, and to examine the influence of nearby clouds on dust. Our analysis suggests that (1) under clear skies, while lidar backscatter and color ratio do not change much with altitude and longitude in the Saharan Air Layer (SAL), depolarization ratio increases with altitude and decreases westward in the SAL; (2) the vertical lapse rate of dust depolarization ratio, introduced here, increases within SAL as plumes move westward; (3) nearby clouds barely affect the backscatter and color ratio of dust volumes within SAL but not so below SAL. Moreover, the presence of nearby clouds tends to decrease the depolarization of dust volumes within SAL. Finally, (4) the odds of CALIOP finding dust below SAL next to clouds are about $2 / 3$ of those far away from clouds. This feature, together with an apparent increase in depolarization ratio near clouds, indicates that particles in some dust volumes loose asphericity in the humid air near clouds, and cannot be identified by CALIPSO as dust.
\end{abstract}

\section{Introduction}

Atmospheric mineral dust particles have significant effects on the climate and the environment. Despite notable advances in modeling and satellite and ground-based measurements, dust remains the dominant factor in the uncertainty of aerosol radiative forcing (IPCC, 2001, 2007). Dust emitted from dry areas of Africa is transported over the North Atlantic Ocean to coastal areas of America with a peak of deposition during summer months (e.g., Prospero and Carlson, 1972; Mattsson and Nihlen, 1996; Prospero and Lamb, 2003; Torres et al., 2002; Kaufman et al., 2005).

The influence of dust on a radiative budget depends on its ability for absorbing and scattering solar and IR radiation. Dust optical properties are determined by the refractive index (i.e., chemical composition) (e.g., Sokolik and Toon, 1999; Wang et al., 2002; Lafon et al., 2006; Kahnert et al., 2007; Kandler et al., 2007, 2009; Osborne et al., 2008; Petzold et al., 2009), size and shape of dust particles (Kalashnikova and Sokolik, 2002; Dubovik et al., 2006; Nousiainen, 2009). Dust hygroscopicity describes the particles' ability for taking up water from humid air, and is rooted in the physical-chemical properties of dust components. Dust is mostly composed of water-insoluble minerals and shows nearly complete hydrophobicity or at least poor hygroscopicity (e.g. Twomey, 1977; Li-Jones et al., 1998; Kaaden et al, 2009; Schladitz et al., 2011; Ansmann et al., 2011). However, after being 
lifted in the air and mixed/coated with water-soluble materials such as sea-salt, sulfate, or nitrate by atmospheric processing (Levin et al., 1996; Yin et al., 2002), dust hygroscopicity can increase, which can cause changes in optical properties. In addition to mineral dust particles serving as ice nuclei (IN) (e.g. DeMott et al., 2003; Ansmann et al. 2008), the increase in hygroscopicity may also transform dust into effective cloud condensation nuclei (CCN) (Johnson, 1982; Wurzler et al., 2000; Sassen et al., 2003; Lohmann and Feichter, 2005; Twohy et al., 2009a) and thereby affect the formation and distribution of clouds and precipitation (e.g. Kelly et al., 2007), thus also altering the radiative impact of clouds.

The evolving shape-dependent optical and hygroscopic properties of dust pose a question: how does the hygroscopicity of dust affect its optical properties near clouds? This question is pertinent as recent studies have shown that optical properties of clear sky aerosols are different in the vicinity of clouds from those far away from clouds (e.g., Clarke et al. 2002; Twohy, et al, 2002, 2009b; Koren et al., 2007; Su et al., 2008; Redemann et al., 2009; Tackett and Girolamo, 2009; Várnai and Marshak, 2011). The answer to this question is likely not only to improve our understanding of dust-cloud interactions but also yield better estimates of direct radiative forcing. To that end, we present analysis of dust properties over the North Atlantic Ocean - including near-cloud behavior - based on Cloud-Aerosol Lidar with Orthogonal Polarization (CALIOP) data (Winker, et al. 2003).

CALIOP is a space based lidar system onboard the Cloud Aerosol Lidar and Infrared Pathfinder Satellite Observations (CALIPSO) satellite launched in 2006. CALIOP data offers many advantages for this study. First, since CALIOP uses a laser with a small footprint $(\sim 90 \mathrm{~m}$ in diameter on the ground), its aerosol data is not affected by the 3-D radiative enhancements of nearby clouds, which cause complications for instruments observing reflected sunlight (Wen et al., 2007; Marshak et al., 2008; Várnai and Marshak, 2011). Second, CALIOP provides backscatter depolarization information at $532 \mathrm{~nm}$, which allows one to distinguish (typically) non-spherical dust from (typically) spherical droplets (Sassen, 2000; Murayama et al., 2001; Vaughan et al., 2004). Third, CALIOP's high spatial resolution (30 m vertically and $333 \mathrm{~m}$ horizontally) is well-suited for studying cloud-dust interactions that have typical scales of several kilometers (e.g., Koren et al., 2007; Várnai and Marshak, 2011). One concern, on the other hand, is that off-track clouds not detected by the lidar beam also affect the observed clear-sky volumes. However, the recent study of co-located MODIS and CALIPSO observations demonstrates that off-track clouds do not qualitatively change the aerosol property trends obtained from CALIOP data alone, and that the contributions from off-track clouds can be taken into account by using a scaling factor (Várnai and Marshak, 2012.)

\section{Data and methodology}

This study uses a month-long (7 June-7 July 2007) dataset of nighttime CALIOP Version 3 data over the North Atlantic Ocean $\left(0-45^{\circ} \mathrm{N}, 0-90^{\circ} \mathrm{W}\right)$. We note that since CALIPSO orbits are repeated in a 16-day cycle, our month-long dataset covers almost two orbital cycles, with the longitudes of closest orbits being $1.55^{\circ}$ apart. Since in summer there are usually multiple outbreaks per month (Huang et al., 2010), this month-long dataset is sufficiently long to observe the basic features of dust outbreaks and also sufficiently short to reduce the impact of temporal changes in dust origin and mixing with other aerosols.

CALIOP measures the total backscatter of its laser pulses at $532 \mathrm{~nm}$ and $1064 \mathrm{~nm}$ wavelengths, and the perpendicularly polarized backscatter at $532 \mathrm{~nm}$. It also reports two complimentary sets of properties for each identified aerosol layer at $5 \mathrm{~km}$ horizontal resolution: measured properties and derived particulate properties. Layer measured properties include integrated attenuated backscatter $\gamma^{\prime}$, integrated attenuated total color ratio $\chi^{\prime}$, integrated volume depolarization ratio $\delta^{\prime}$, while the corresponding layer derived particulate properties include optical depth $(\tau)$, integrated particulate color ratio $(\chi)$, integrated particulate depolarization ratio $(\delta)$. These products allow us to obtain attenuated volume backscatter coefficient values $\beta^{\prime}$ by dividing the integrated attenuated backscatter values by the layer geometrical thickness.

This paper analyzes dust observations mostly using attenuated volume properties. These properties are direct measurements without potential artifacts induced by assumptions and are thus suitable for describing the direct observations. On the other hand, since the retrieved dust particulate properties are free of molecular Rayleigh scattering and gas attenuation, they will also be used for better understanding the physics behind the observations. The results based on particulate properties are shown in the Appendix.

In distinguishing dust from clouds and other aerosols we rely on the operational CALIOP aerosol product. The operational algorithm identifies cloud and dust layers in three steps.

First, it identifies particle layers based on the observed $532 \mathrm{~nm}$ backscatter values (Winker et al., 2009; Vaughan et al., 2009).

Second, it determines whether a detected layer is a cloud or aerosol layer based on its latitude, altitude, $532 \mathrm{~nm}$ backscatter, color ratio and depolarization ratio (Liu et al., 2004, 2009). The most obvious clouds are identified at $333 \mathrm{~m}$ resolution, while the more ambiguous cases are decided at a coarser $(1$ or $5 \mathrm{~km})$ resolution. Our study considers a location cloudy if the $1 \mathrm{~km}$ resolution Level 2 CALIOP cloud product indicates the presence of clouds. In order to reduce the impact of misclassifications between clouds and aerosols, this paper examines aerosol layers only if the Cloud-Aerosol Discrimination (CAD) product (Liu et al., 2004, 2009) - based on probability distribution functions obtained from expert 

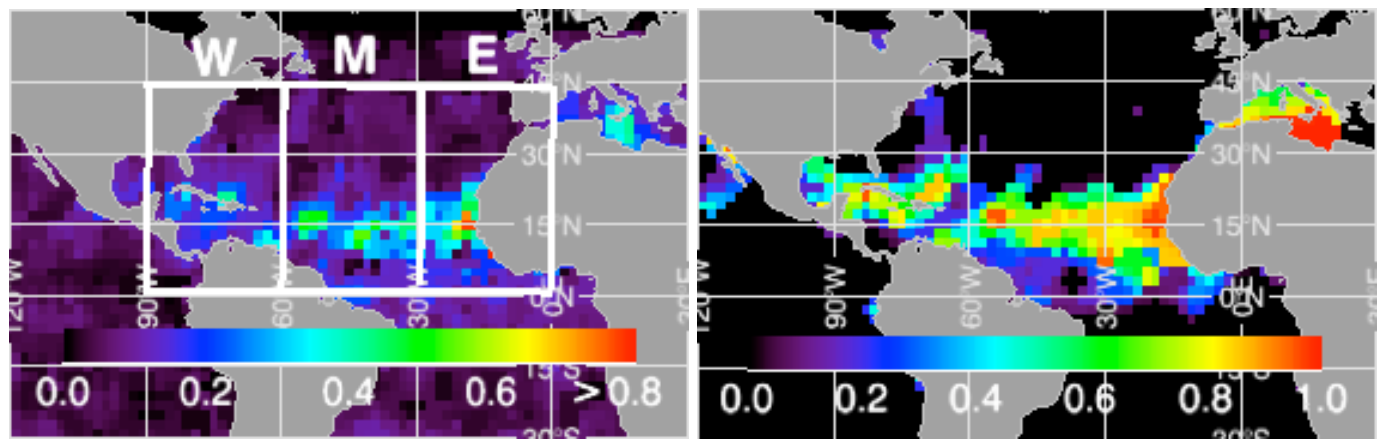

Fig. 1. Location of the 3 North-Atlantic regions examined in this study. Colors indicate the nighttime CALIOP Aerosol Optical Depth (AOD) contributed from all aerosols (left), and fraction percentage of the dust contribution to AOD (right) over oceans for the 7 June-7 July 2007 period, at a pixel resolution of $2^{\circ} \times 2^{\circ}$.

classifications for sample orbits - indicates that the likelihood of misclassification is less than $15 \%$. We note, however, that this is only the worst case, as for most layers used in our study the operational algorithm indicates a much lower probability of misclassification. Since altitude and depolarization ratio are also considered in the current (Version 3) CAD algorithm, the operational processing separates ice clouds from dust in this step. We note that limiting our analysis to altitudes below $5 \mathrm{~km}$ and summer is also likely to reduce the misclassification rate. As additional precaution, the statistical analysis in this paper examines median values instead of mean values, because medians are less sensitive to any outlying data points influenced by undetected cloud particles. The uncertainty of median values is estimated using the bootstrapping algorithm (Efron and Gong, 1983).

Third, the operational CALIOP data processing identifies dust layers as aerosol layers with high depolarization ratio values (Omar et al, 2009). Because depolarization depends on particle shape, it is well suited for separating typically non-spherical dust particles $(\delta>0.2)$ from usually spherical non-dust aerosols $(\delta<0.075)$ over ocean. We note that this paper considers dust-containing aerosol layers identified as either "dust" or "polluted dust" in the $5 \mathrm{~km}$-resolution Level 2 aerosol product. (Polluted dust is dust mixed with biomass burning aerosols or polluted marine aerosols, with a depolarization ratio between those of dust and non-dust aerosols, 0.075 and 0.2 as discussed in Omar et al., 2009).

To discern changes in dust properties during transatlantic transport, we examine dust behavior in the three regions shown in Fig. 1: east $(\mathrm{E})\left(0-30^{\circ} \mathrm{W}\right)$, middle $(\mathrm{M})\left(30-60^{\circ} \mathrm{W}\right)$ and west $(\mathrm{W})\left(60-90^{\circ} \mathrm{W}\right)$. These three regions lie at different distances from the African dust sources, and cover most of the dust paths from Africa to America during the summer of 2007.

\section{Results and discussion}

The spatial and optical characteristics of African dust vary during the transatlantic journey (e.g., Liu et al., 2008; Huang et al., 2010). In this section we examine the variations in three steps. First, the overall statistics of dust properties in the three geographic regions are compared. This part focuses on the vertical distribution of dust samples in the CALIOP $5 \mathrm{~km}$ resolution aerosol product, and on the vertical distributions of attenuated backscatter coefficient, color ratio and depolarization ratio. We then analyze the relationships between dust properties and cloud coverage in the three regions. Finally, we discuss the systematic changes in dust properties that occur near clouds.

In recent years there has been a large amount of research conducted on characterizing the physical, chemical properties of Saharan mineral dust during its transport, such as Saharan Dust Experiment (SHADE) (e.g. Tanré et al., 2003), Puerto Rico Dust Experiment (PRIDE) (e.g. Reid and Maring, 2003), African Monsoon Multidisciplinary Analysis (AMMA) (e.g. Redelsperger et al., 2006), and Saharan Mineral Dust Experiment (SAMUM) (e.g. Heintzenberg et al., 2009; Ansmann et al, 2011), etc. By using the capabilities of various lidars, dust profiling (e.g. Freudenthaler et al, 2009; Ansmann et al, 2009; Tesche et al., 2009, 2011) has provided insights into the vertical distributions of size, shape, extinction and scattering of mineral dust at various sites and seasons.

Compared to the above mentioned field experiments, this paper examines dust properties and the influence of clouds during transport based on a larger datasets that includes three consecutive regions along a typical transport path during summer. Also, the statistics is conditioned upon the presence of dust layers identified by CALIOP. 

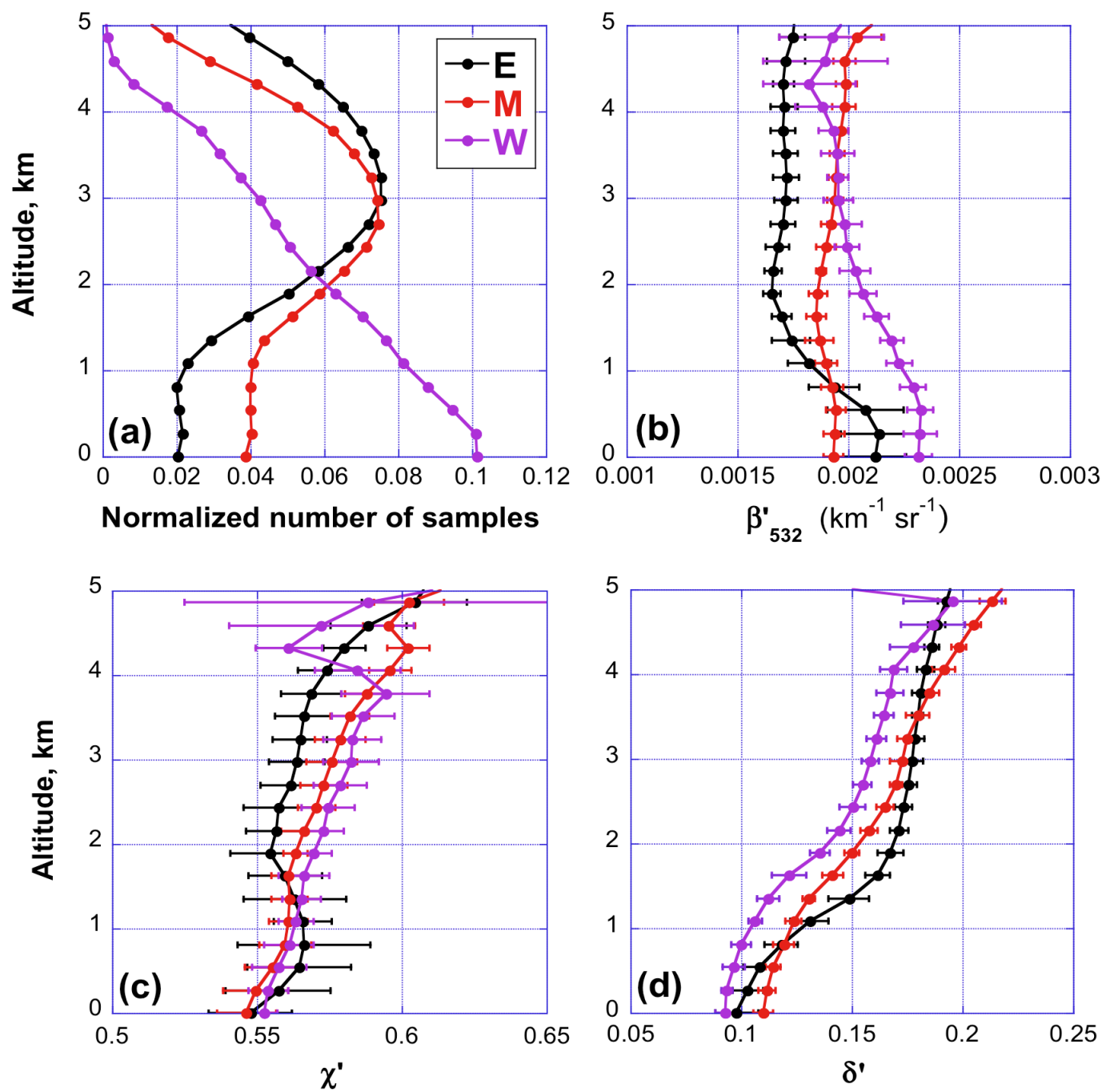

Fig. 2. Vertical profiles of (a) number of $5 \mathrm{~km}$-resolution dust samples, normalized by the total number of dust samples at each corresponding region. The total number of dust samples is 45714 for E, 73141 for $\mathrm{M}$ and 32785 for W. In addition, the E, M, and W regions contain 24701 , 34 019, and $237865 \mathrm{~km}$-resolution vertical profiles over ocean, respectively. (b) median attenuated total backscatter coefficient at $532 \mathrm{~nm}$, $\beta_{532}^{\prime}$, (c) median attenuated color ratio, $\chi^{\prime}$, (d) median volume depolarization ratio, $\delta^{\prime}$. The colors identify the profiles for each study region (East, Middle, and West). The error bars indicate the uncertainty of median values, estimated using the bootstrap algorithm.

\subsection{Dust properties in the three regions}

\subsubsection{Vertical distribution of dust}

Figure 2a shows the vertical distribution of dust samples in our three regions, normalized by the total number of dust samples within each region. The number of dust samples is defined as the number of $5 \mathrm{~km}$ long $270 \mathrm{~m}$ high volumes that, according to the CALIOP aerosol product, contain dust and have a CAD value between -70 and -100 . In the Eastern (E) region, more than $80 \%$ of dust is between $1.5 \mathrm{~km}$ and $5.5 \mathrm{~km}$ altitude, with the peak probability around $3.5 \mathrm{~km}$. This elevated dust distribution is a typical result of two confining inversions below and above the SAL (Carlson and Prospero,
1972). The dust remains elevated in the middle (M) region as well, although the mean elevation descends about $0.5 \mathrm{~km}$. If a 3-day average transport time from Region $\mathrm{E}$ to $\mathrm{M}$ is assumed, the descending velocity from center of $E$ to center of $\mathrm{M}$ is estimated around $1.7 \mathrm{~mm} \mathrm{~s}^{-1}$, which is consistent with the typical SAL average descending velocity of $1-2 \mathrm{~mm} \mathrm{~s}^{-1}$ (Carlson and Prospero, 1972). Finally, in the West (W) region the chances of finding dust decrease steadily with altitude, and dust is rarely found above $5 \mathrm{~km}$. This dramatic change in the vertical distribution implies that the meteorological conditions in region $\mathrm{W}$ are different from those sustaining the elevated profiles in regions E and M. Moreover, the vertical distribution of dust in region $\mathrm{W}$ indicates that (dry and wet) dust sedimentation has the strongest impact over region $\mathrm{W}$. 


\subsubsection{Attenuated backscatter coefficient, color ratio, and depolarization ratio of dust}

This section examines dust optical properties in the three regions. Since dust above $5 \mathrm{~km}$ is rare, the analysis of dust optical properties will be limited to altitudes below $5 \mathrm{~km}$. The analysis uses the Level 2 CALIOP aerosol layer product, which provides averaged volume properties of $\beta^{\prime}, \chi^{\prime}$, and $\delta^{\prime}$ as well as their particulate counterparts $\chi$ and $\delta$ for each dust layer. These layer-average values are assigned to all altitude bins within a dust layer when creating Fig. 2 (and 4) as well as Figs. A1 (and A2) in the Appendix.

The results in Figs. 2 and A1 show that dust properties vary with altitude differently within SAL (from 1.5 to $5 \mathrm{~km}$ in altitude of regions $\mathrm{E}$ and $\mathrm{M}$ ), below the SAL (below $1.5 \mathrm{~km}$ in regions $\mathrm{E}$ and $\mathrm{M}$ ), and in region $\mathrm{W}$.

In the SAL, median $\beta_{532}^{\prime}$ values are nearly constant with altitude, but the medians of $\chi^{\prime}$ and $\delta^{\prime}$ as well as $\chi$ and $\delta$ increase with altitude. The increase of $\chi^{\prime}$ and $\chi$ implies increase in size if particles are spherical. However, because of the complex relationship between size and color ratio for aspherical particles (Bi et al., 2009), the slight increase of color ratio here does not imply increase of dust size. Moreover, further analysis in Sect. 3.2 shows the dust color ratio under clear skies to vary insignificantly with altitude. The increase of $\delta^{\prime}$ and $\delta$, on the other hand, suggests that asphericity of dust increases with altitude and/or the concentration of mixed marine aerosols in dust volumes decreases with altitude, since large asphericity of dust particles implies large $\delta$.

Below the SAL in the regions $\mathrm{E}$ and $\mathrm{M}$, the median $\delta^{\prime}$ (as well as $\delta$ ) increases with altitude. This is the result of dust mixing with non-dust marine aerosols in the moist air confined between the marine surface and the inversion created by the dry and warm SAL aloft. Since the concentration of wet marine aerosols is much higher below than inside the SAL, backscatter from these aerosols contributes significantly to the lidar signals and reduce the depolarization ratios of dust volumes below the SAL.

In region $\mathrm{W}$, the median of $\beta_{532}^{\prime}$ decreases with altitude and the medians of $\chi^{\prime}$ and $\delta^{\prime}$ (as well as $\chi$ and $\delta$ ) increase with altitude. Similar to the case in the $\mathrm{E}$ and $\mathrm{M}$, the increase in color ratio does not necessarily imply the increase of dust size, while the increase of depolarization ratio indicates the increase of dust asphericity and/or decrease of concentration of marine aerosols mixed in dust volumes at higher altitude. The median of $\beta_{532}^{\prime}$ decreasing with altitude is the direct result of reduced dust and/or marine aerosol concentration at higher altitudes.

A comparison of dust properties in regions $\mathrm{E}, \mathrm{M}$, and $\mathrm{W}$ also reveals several features at different transport stages. For example, at most altitudes the medians of $\beta_{532}^{\prime}$ and $\chi^{\prime}$ increase westward, whereas the median of $\delta^{\prime}$ (and of $\chi$ and $\delta$ ) tends to decrease westward. We note that the further study of fully cloud-free regions in Sect. 3.2 indicates westward $\beta_{532}^{\prime}$ increases only below $\sim 2 \mathrm{~km}$, with no significant westward changes above $2 \mathrm{~km}$. The westward increase of $\beta_{532}^{\prime}$ below $2 \mathrm{~km}$ is likely the result of mixing with higher concentration of marine aerosols in the $\mathrm{W}$ than in E. Monthly data from the Goddard Earth Observing System Model Version 5 (GEOS-5) Modern Era Retrospective-Analysis for Research and Applications (MERRA) for June 2007 shows increasing surface wind speed westward along the dust path in Figure 1 , with values around $\sim 13 \mathrm{~m} \mathrm{~s}^{-1}, \sim 9 \mathrm{~m} \mathrm{~s}^{-1}$ and $\sim 2 \mathrm{~m} \mathrm{~s}^{-1}$ at $850.0 \mathrm{hPa}$ at $15^{\circ} \mathrm{N}$ latitude for the $\mathrm{W}, \mathrm{M}$, and $\mathrm{E}$ regions. A westward increase in wind speed is also observed by Davidi et al. (2012). The stronger surface wind speed generates higher concentration of marine aerosols and better mixing with dust towards the $\mathrm{W}$. This is consistent with the observed westward trend of decreasing particulate $\delta$.

The westward decreasing trend of depolarization ratio below the SAL also suggests that the amount of marine aerosols mixed with dust in the Marine Boundary Layer (MBL) increases westward. This issue will be further explored in Sect. 3.2, which also considers the influence of cloudiness.

However, some features in Fig. 2 cannot be explained by contributions from non-dust marine aerosols in dust sample volumes, and are likely caused by changes in the properties of dust particles instead. For example, Fig. 2d shows that above $3.5 \mathrm{~km}$, the median $\delta^{\prime}$ is larger in region $\mathrm{M}$ than in region $\mathrm{E}$. The features remain similar for $\delta$ in as shown in Fig. A1. This cannot be explained by mixing from below or more well-mixing westward, because the mixing at high altitude of SAL (above $3.5 \mathrm{~km}$ ) is rare. Instead, the observed tendency is likely related to lower fall speed for aspherical dust particles: as the more spherical particles fall faster, this leaves an increasingly non-spherical dust population at high altitudes as the air moves to region $\mathrm{M}$. The plausibility of this scenario is also supported by simulations for highly irregular particles falling slower than more spherical ones, because of greater air resistance (Ginoux, 2003). This issue will be further discussed in Sect. 3.3.2.

We note that the slight increase of $\chi^{\prime}$ or decrease of $\chi$ of dust volumes from $\mathrm{E}$ to $\mathrm{M}$ (in Figs. $2 \mathrm{c}$ and $\mathrm{A} 1$ ) appears different from the behavior of dust Angstrom exponents retrieved by MISR and MODIS, the latter displaying no significant changes during transatlantic transport (Kalashnikova and Kahn, 2008). This apparent difference can be removed when we examine the color ratios under clear skies as discussed in Sect. 3.2, in which no significant difference in color ratio is found in all 3 regions.

\subsection{Correlation of dust properties with cloud fraction}

This section examines the relationships between dust properties and cloudiness in the three study regions. We characterize cloudiness through the cloud fraction $(\mathrm{CF})$, defined for each dust-containing $5 \mathrm{~km}$-size column as the ratio of number of cloudy $0.333 \mathrm{~km}$ profiles to the total number of $0.333 \mathrm{~km}$ profiles in the column. Simply put, if the number of cloudy 
$0.333 \mathrm{~km}$ profiles is $m$, the cloud fraction is $m 15^{-1}$. We note that in addition to the cloud fraction varying between 0 and 1 , the relative location of dust and clouds within $5 \mathrm{~km}$ wide columns can also vary (Fig. 3). We also note that unlike the conventional cloud fraction that is based on 2-dimensional (2-D) images, our definition here is based on 1-dimensional (1-D) measurements along the CALIPSO track. Although off-track clouds may influence dust properties along the track even for $\mathrm{CF}_{1-\mathrm{D}}=0$, there is direct statistical relationship between the defined $\mathrm{CF}_{1-\mathrm{D}}$ here and the conventional $\mathrm{CF}_{2-\mathrm{D}}$ (Várnai and Marshak, 2012), and $\mathrm{CF}_{1-\mathrm{D}}$ is still a generally useful indicator of cloud coverage.

The results in Fig. 4 show that dust properties are closely related to $\mathrm{CF}$ in all three regions. The main features of the relationship are as follows.

First, the top row of Fig. 4 reveals that a smaller fraction of dust samples occurs under clear skies in region $M$ than in region E. This is because the SAL is warmer and drier in the East, and so the conditions are less favorable for cloud formation in region $\mathrm{E}$ than region $\mathrm{M}$.

Second, rows 2 and 3 in Fig. 4 reveal that within each region, the median values of $\beta_{532}^{\prime}$ and $\chi^{\prime}$ are larger for higher CF's. This feature is likely caused by aerosols getting hydrated and swelling in humid regions containing clouds, although undetected cloud particles may also contribute. The figure also shows that in regions $\mathrm{E}$ and $\mathrm{M}$, the increase in backscatter and color ratio is more pronounced below the SAL than inside it. The swelling is greater below the SAL than inside it both because clouds and high humidity are more common below the SAL, and because hygroscopic marine aerosols are fairly abundant at low altitudes even in dust layers, whereas the SAL is dominated by less hygroscopic dust particles.

Third, within each region, two opposite trends of correlations appear between $\delta^{\prime}$ and CF: inside the SAL, the median $\delta^{\prime}$ of dust is always larger in clear sky than in cloudy skies; whereas below the SAL, the median $\delta^{\prime}$ of dust is always smaller in clear sky than in cloudy skies. The domains of these opposite behaviors can be separated in the fourth row of Fig. 4 roughly at the crossing point of the red curve $(\mathrm{CF}=0)$ and the blue curve $(0<\mathrm{CF}<0.6)$. We note that these crossing points are approximately at the altitude of the bottom of the SAL. The opposite trends inside and below the SAL clearly indicate a different dust volume depolarization response to increased humidity. The possible mechanisms affecting the apparent depolarization ratio of dust volumes below the SAL will be discussed in Sect. 3.4.

It should be also noted that since the dust layers discussed in this subsection include those below clouds, the quality of lidar signals returned from such dust may have been degraded by the clouds above. This can further affect the retrieved dust particulate properties seen in Fig. A2. Therefore the discussion of CF influence is based on using the volume property here instead of using retrieved particulate property. However, since signals from dust layers under clear skies are
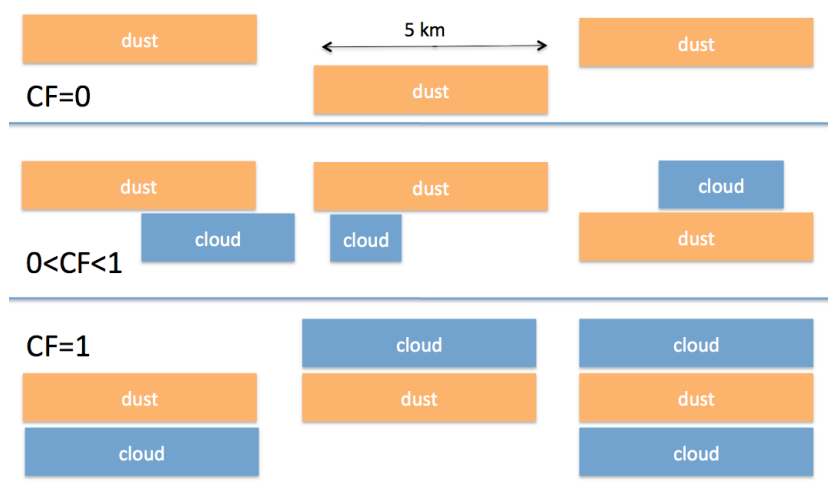

Fig. 3. Schematic illustration of Cloud Fraction (CF) definitions for $5 \mathrm{~km}$ resolution dust pixels. CF is the fraction of cloudy $0.3 \mathrm{~km}-$ resolution pixels in $5 \mathrm{~km}$ size areas containing dust.

not affected by clouds above, particulate properties (Fig. A2) for $\mathrm{CF}=0$ reflect dust properties without quality degrading effects from clouds.

\subsection{Features of dust volumes in the SAL under clear skies}

Unlike the dust volumes below the SAL, where the dust is mixed with humidified non-dust aerosols, the SAL is dominated by dust particles. This subsection examines several features of dust volumes inside the SAL in regions $\mathrm{E}$ and $\mathrm{M}$. To reduce the effects of clouds, dust volumes are limited to only those under clear skies. In addition, region $\mathrm{W}$ is excluded because of its low number of dust samples inside the SAL (Fig. 2a).

\subsubsection{Relationship of depolarization ratio with color ratio}

Figures 2 and 4 show that while backscatter is fairly uniform vertically, both color ratio and depolarization ratio increase markedly with altitude inside the SAL of regions $\mathrm{E}$ and $\mathrm{M}$. These coinciding increases suggest systematic relationship between the depolarization and color ratio (Fig. 5). Figure 5a reveals a positive relationship between the depolarization ratio and color ratio of dust volumes in the SAL of regions $\mathrm{E}$ and $\mathrm{M}$. In addition, the dynamic ranges of depolarization ratio and color ratio are much wider in region $M$ than in region E. Figure $5 b$ confirms that similar relationships are valid for a different dataset (covering 25 May-25 June 2008) as well.

The relationships shown in Fig. 5 and the similarity of results from the two independent datasets can be attributed to the steady altitude-dependence of color ratio and depolarization ratio inside the SAL. As discussed in Sect. 3.1.2, these altitude dependences are likely caused by two mechanisms: (i) a decrease with altitude in the concentration of non-dust particles mixed in from below, and (ii) different fall speeds vertically separating the relatively more spherical dust 

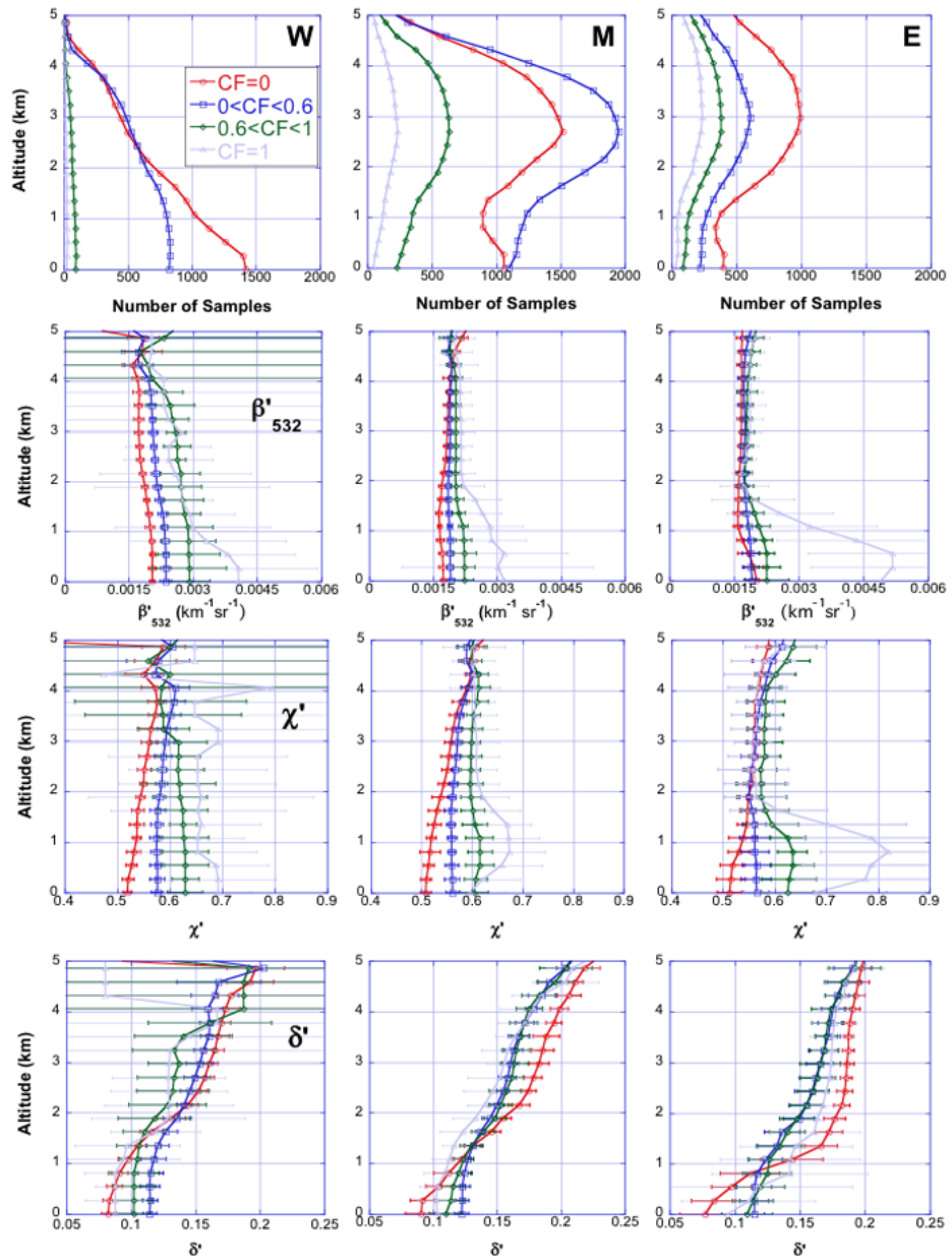

Fig. 4. Vertical profiles of dust properties for various cloud fractions at the 3 regions. Rows 1, 2, 3 and 4 are for frequency of occurrence, attenuated total backscatter coefficient at $532 \mathrm{~nm}, \beta_{532}^{\prime}$, attenuated color ratio, $\chi^{\prime}$, and volume depolarization ratio, $\delta^{\prime}$, respectively. The left, center, and right columns show the West, Middle and East regions, respectively. Results for different cloud fractions are indicated by different colors. 

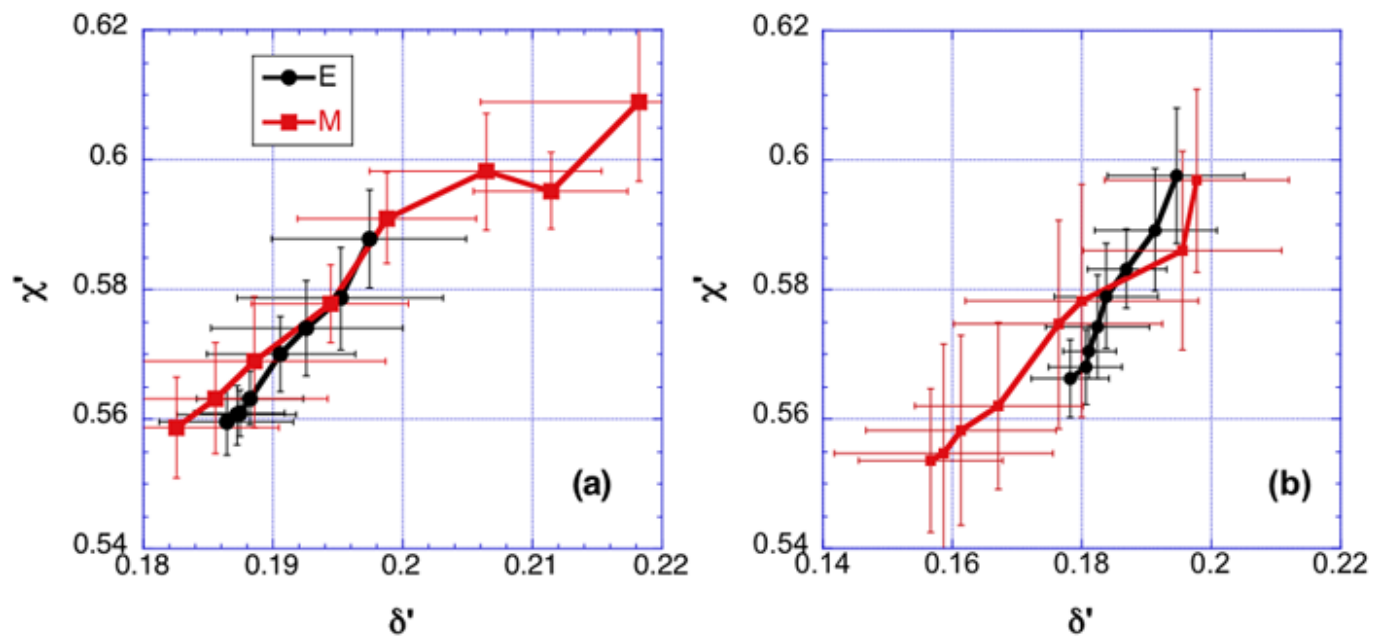

Fig. 5. Median depolarization ratio, $\delta^{\prime}$, as a function of color ratio, $\chi^{\prime}$ (a). As in Fig. 2, colors identify the examined regions E (black) and M (red). (b) is the same as (a), but for a different dataset from 25 May to 25 June 2008.

particles from the least spherical ones. This latter mechanism dominates and is further explored in Sect. 3.3.2. In addition, we note that the depolarization ratio is predominantly influenced by asphericity of the dust particles (e.g. Ansmann et al., 2003).

\subsubsection{Relationship between the vertical increase in depolarization ratio and longitude}

As indicated in Figs. 2 and A1, the depolarization ratio not only increases with altitude in the SAL, but also has a larger increase rate in region $\mathrm{M}$ than $\mathrm{E}$. As mentioned above, the increase may come from more spherical and less spherical dust particles getting vertically separated because of their different sedimentation speeds. The upward increase in $\delta^{\prime}$ and $\delta$ could then be stronger in region M simply because the sedimentation process has more time to work by the time the dust reaches region $\mathrm{M}$.

Numerous studies have demonstrated that the fall speed of atmospheric particles depends on their shape (e.g., Cheng et al., 1988; Ginoux, 2003) as well as size. Since particles with irregular shapes have greater cross-sectional areas and dragcoefficients, they experience stronger drag force in the air which implies that more irregular particles of the same mass fall slower than more spherical ones. Note that a sphere is the most compact object (least surface area for a given volume) and it experiences least drag for a given mass. (Here we assume that dust particle shape does not change systematically with particle size, which also greatly impacts fall speed. This assumption is plausible because field experiments show that distribution of aspect ratio is weakly related to particle size; e.g. Chou et al., 2008; Kandler et al., 2009.) As a result, shape-induced vertical separation will ensue as dust is advected westward, with irregular particles increasingly predominant in the upper portions of SAL. At a constant altitude, this stratification is expected to widen the dynamic range of depolarization ratios with downstream distance from the dust source. This is indeed the case.

To that end, we divide regions $\mathrm{E}$ and $\mathrm{M}$ into sub-regions covering $10^{\circ}$ wide longitude bands, and examine the average difference between the depolarization ratios at 3 and $4 \mathrm{~km}$ altitudes for each region. As shown in Fig. 6 (and Fig. A4), the average difference $\delta_{4 \mathrm{~km}}^{\prime}-\delta_{3 \mathrm{~km}}^{\prime}\left(\right.$ or $\left.\delta_{4} \mathrm{~km}-\delta_{3 \mathrm{~km}}\right)$ keeps increasing with the distance from the west coast of Africa. This result implies that the observed change in volume depolarization ratio within SAL is most likely caused by the greater drag of aspherical dust particles. In addition, this result is consistent with the observation of higher aspect ratio of long rang transported Saharan dust Reid et al. (2003).

\subsection{Dust volume properties near clouds}

Relative humidity usually increases as clouds are approached and this causes nearby aerosols to swell and get hydrated (acquire thin film of water) or even activated as haze (e.g., Twohy et al., 2009b). Observing changes of dust characteristics near clouds can help improve our understanding of the effect of high relative humidity and clouds on dust particles. Figure 4 has shown that the backscatter $\beta^{\prime}$ and color ratio $\chi^{\prime}$ of dust volumes increase with cloud fraction both in and below the SAL, whereas the depolarization ratio $\delta^{\prime}$ changes with cloud fraction differently in and below the SAL. This finding indicates that dust properties in and below the SAL are different. This section further examines the near cloud behaviors of dust volumes in and below the SAL. We note that although the base altitude of the SAL may vary during westward transport, as shown in Figs. 2 and 4, this analysis uses constant separation altitude of $2 \mathrm{~km}$ for convenience. Since there is no aerosol particulate retrieval available at resolutions higher than $5 \mathrm{~km}$, our analysis uses CALIOP Level 1 


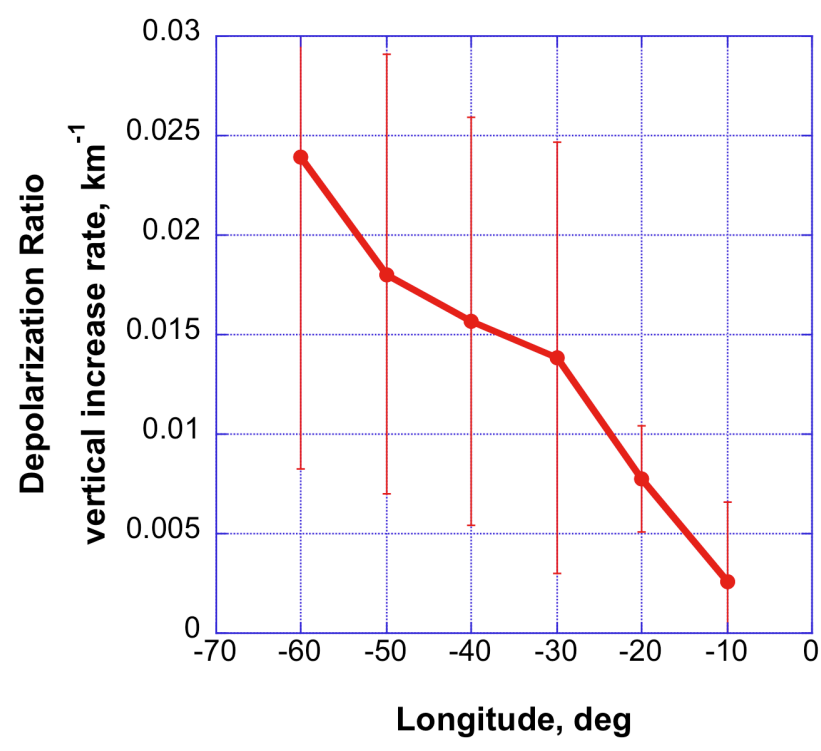

Fig. 6. Rate of vertical increase in dust depolarization ratio between 3 and $4 \mathrm{~km}$ altitudes, vs. distance from the African coast, represented by longitude. Particle shape-dependent differences in fall speed cause increasingly more pronounced vertical stratification as plumes move westward.

data to examine changes in backscatter, color ratio, and depolarization as a function of distance to clouds at a resolution of $0.333 \mathrm{~km}$. In this analysis a $0.333 \mathrm{~km}$ resolution clear sky profile is considered a dust profile if it is included in one or multiple $5 \mathrm{~km}$ resolution dust layer(s). Moreover, a clear sky requirement of no $0.333 \mathrm{~km}, 1.0$ and $5 \mathrm{~km}$ clouds above or below used in selecting dust profiles near clouds avoids the signal degradation mentioned in the previous subsection earlier.

Figure 7 illustrates the behavior of dust as a function of distance to clouds. The orange curve corresponds to all aerosol samples while the black and green ones to high (in the SAL) and low (below the SAL) dust, respectively. Figure 7a shows that the fraction of dust profiles over all detected aerosol profiles decreases dramatically near clouds for dust at altitudes below the SAL, but remains relatively stable for those in the SAL. The stable behavior in the SAL can be explained by the fact that low clouds confined to the boundary layer by the inversion at the base of the SAL have little impact on humidity inside the SAL. The near-cloud drop in the fraction of dust profiles below the SAL may result from several factors. First, the chances of wet removal are higher near clouds, and this can lower the fraction of dust profiles. Second, swelling in the humid air near clouds makes particles more spherical (especially if water-soluble particles pollute dust crystals), resulting in the reduction of depolarization ratio thus the dust signature (Omar et al., 2009); consequently, some dust-containing profiles are (mis)classified as non-dust aerosol. Assuming that below $2 \mathrm{~km}$ altitude, the fraction of dust profiles is constant beyond $5 \mathrm{~km}$ from clouds (as most humidity changes occur within $5 \mathrm{~km}$ from clouds), the roughly $2 / 3$ drop in the fraction of dust profiles near clouds implies that at least $2 / 3$ of dust profiles in the MBL are polluted and hygroscopic. This results in CALIOP missing dust in about $1 / 3$ of dust profiles that occur within $5 \mathrm{~km}$ from clouds.

Figure $7 \mathrm{~b}$ an $\mathrm{d}$ also show that backscatter, color ratio, and depolarization ratio all increase near clouds for dust layers below $2 \mathrm{~km}$, but they remain fairly constant for dust layers above $2 \mathrm{~km}$. The stable behavior in the SAL occurs because most clouds are below the SAL and have little impact on dust in the SAL. In addition, the dust population in the SAL is dominated by hydrophobic particles. For dust volumes below $2 \mathrm{~km}$, the enhanced backscatter and color ratio may come from the swelling of hygroscopic dust and nondust particles in the humid air near clouds, or even from cloud contamination. However, the depolarization ratio is expected to decrease and not increase near clouds, as hydrated particles tend to be more spherical than dry particles. Thus the apparent increase in depolarization ratio near clouds for dust volumes below $2 \mathrm{~km}$ is somewhat counter-intuitive. This counter-intuitive feature of $\delta^{\prime}$ near clouds remains the same for the estimated particulate depolarization ratio $\delta$ in Fig. A5. A possible explanation is that the hydrated and more spherical dust particles or those heavily mixed with marine aerosols are (mis)classified as non-dust aerosols due to their reduced depolarization ratio; the remaining particle populations will be dominated by hydrophobic dust particles that have irregular shapes and hence higher depolarization ratios.

In principle, multiple scattering by undetected cloud fragments could also increase depolarization, but this is likely insignificant, for two reasons: (i) the increase in backscatter is too small to suggest strong multiple scattering near clouds, and (ii) the depolarization ratio of all aerosols (orange curve in Fig. 7d) increases only slightly near clouds, which also suggest that cloud contamination should be less significant if any. Another possibility could be that dense dust was misclassified as cloud and the observed trend could come from changes near thick dust, as opposed to near clouds. However, this would increase the fraction of dust profiles near clouds, whereas Fig. 7a shows a decrease: if much of the detected clouds were in fact pockets of dense dust, the fraction of dust profiles should increase near them, as dilute dust profiles are more frequent near dense dust than far from it.

\section{Summary}

This paper uses CALIOP lidar data to examine the bulk optical properties of dust layers as Saharan dust moves westward over the Atlantic Ocean. It analyzes dust layers in three regions along the dust transport route, and examines the relationships between dust properties and the amount and proximity of nearby clouds. 

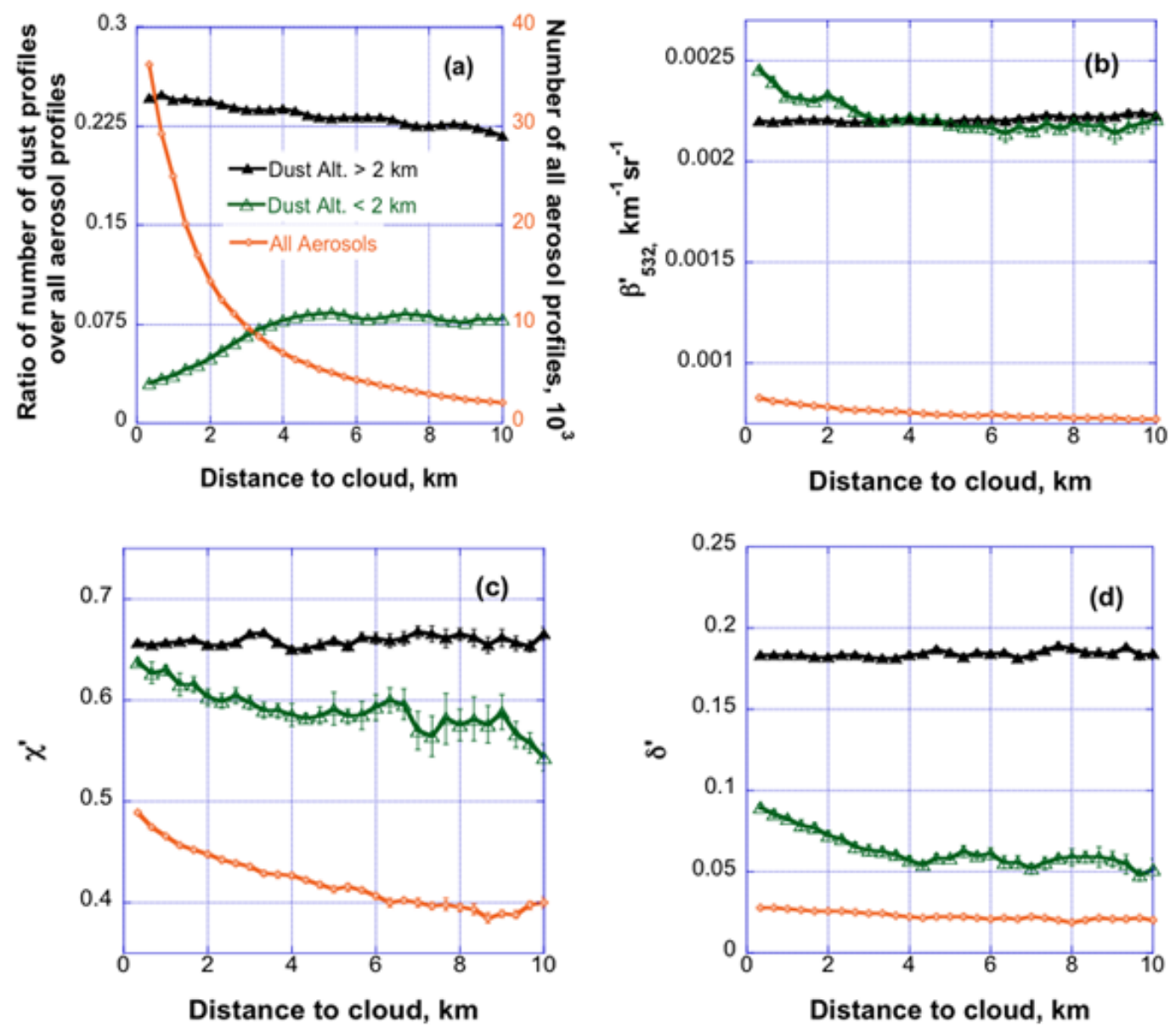

Fig. 7. Properties of high and low dust as a function of distance to clouds, combined for the three regions (W+ M+E): (a) fraction of detected aerosol profiles that contain dust, (b) attenuated backscatter coefficient at $532 \mathrm{~nm}, \beta_{532}^{\prime}$, (c) attenuated color ratio, $\chi^{\prime}$, (d) depolarization ratio, $\delta^{\prime}$. The orange curve in (a) is the number of detected "all aerosol" profiles as a function of distance to clouds. It is also used as denominator in calculating the fraction of high and low dust profiles. Orange curves in (b-d) show the optical properties of all aerosols combined.

The study finds that the observed properties of dust volumes are related not only to the meteorological conditions in the three regions, but also to the speed and duration of dry and wet sedimentation processes. The study examines four characteristics of dust layers: (i) the volume of air containing dust, (ii) lidar backscatter (related to optical thickness), (iii) color ratio (related to particle size at least for spherical particles), and (iv) depolarization ratio (characterizing particle shape, with larger values for irregular particles than for spherical ones). The results show that lidar backscatter and color ratio under clear skies do not change much during transport, while the depolarization ratio is larger in the warmer and dryer East region.

The analysis reveals that the medians of depolarization ratio generally increase with altitude in the SAL. The rate of vertical increase in depolarization ratio is significantly larger farther away from Africa's west coast.

We find that the optical properties of dust volumes are related to cloud coverage, with backscatter and color ratio in- creasing with the cloudiness of surrounding areas. The effects of cloudiness are most prominent for dust below the SAL. The results highlight that sensitivity to cloudiness is very different below and within SAL.

The results also reveal other differences between dust volume near-cloud behaviors inside and below the SAL. In the SAL, the fraction of aerosol samples that contain dust doesn't depend on the distance to clouds, the median lidar backscatter, color ratio, and depolarization ratio. Below the SAL, the fraction of aerosol samples containing dust decreases near clouds, while the optical properties show noteworthy increases near clouds. The unique features of dust below the SAL indicate that in humid air near clouds only some large dust particles with much higher depolarization ratio are identified as dust by the CALIPSO detection algorithm, and these particles become less frequent near clouds.

Earlier studies demonstrated that the degree of irregularity of dust affects dust optical properties and radiative forcing. Our observations further underline the need for assessing the 
effects of vertical separation in dust depolarization, caused by shape-dependent fall velocity, both in transport modeling and in estimating dust radiative forcing. In addition, our observations of near-cloud behaviors reveal the complexity of dust mixing with other water-soluble aerosols especially in the MBL, and support the hypothesis that dust, or the MBL part of it, becomes hygroscopic through interactions with atmospheric components in moist air, and this significantly affects dust optical properties.

\section{Appendix A}

CALIOP measures backscattered signals at two wavelengths, $532 \mathrm{~nm}$ and $1064 \mathrm{~nm}$, and also measures the perpendicularly polarized return signal at $532 \mathrm{~nm}$. For each detected aerosol layer, the CALIOP Level 2 aerosol product reports these measurements as the "volume properties" examined in the main body of this paper. Since, however, the directly measured signals are affected by molecular Rayleigh scattering and by two-way attenuation along the path to the observed aerosol layers, the CALIOP Level 2 aerosol product also includes "particulate properties". These particulate properties are obtained by estimating the contributions of Rayleigh scattering and ozone absorption using GEOS-5 molecular density profiles, and considering aerosol and cloud attenuation above using appropriate typical lidar ratio values.

Since aerosol particulate properties are free of molecular Rayleigh scattering and gas or cloud attenuation, observing the variations in dust particulate properties can help understand changes in dust properties during transatlantic transport and near clouds. This appendix presents dust particulate color ratio and depolarization ratio results that correspond to the volume property results discussed in Sect. 3. For convenience, the figure numbering is parallel to those in main text.

As expected from the volume products, particulate color ratios in the three regions (Fig. A1 left) show increasing trend with altitude. However, they also show a decreasing trend westward that is opposite to westward increasing trend of volume color ratio (Fig. 2a). Particulate depolarization ratio values (Fig. A1 right) show similar trends with altitude and longitude as volume depolarization ratios do (Fig. 2b).

Figure A2 reveals that the dependence on cloud cover that is, the difference between the red curves representing cloud free areas and the other curves - is markedly different for particulate properties than for the volume properties shown in Fig. 4. Dust particulate color ratio is larger for clear skies $(\mathrm{CF}=0)$ than for cloudy skies $(\mathrm{CF} \neq 0)$, while volume color ratio is larger for cloudy skies than for clear skies. Dust particulate depolarization ratio is always larger for clear skies than for cloudy skies, while volume depolarization ratio is larger in clear skies than cloudy skies only above $\sim 2 \mathrm{~km}$.

The particulate properties' dependence on cloudiness may come from swollen non-dust aerosols or undetected cloud particles occurring in dust volumes in cloudy regions: these large spherical particles can increase color ratio and decrease depolarization ratio. We note, however, that if a dust layer is below a cloud layer, attenuation in the cloud above can reduce quality of particulate products. The uncertainties are likely larger for dust particulate properties than for volume properties because of uncertainties in the lidar ratios used for taking cloud attenuation into account when obtaining particulate properties. Under clear skies, however, dust measurements are not affected by clouds above, and particulate properties are likely as accurate as volume properties; their difference comes mainly from well known Rayleigh scattering and ozone absorption.

Figure A3 shows similar positive relationships between the particulate color ratio and depolarization ratio as in Fig. 5. These particulate property relationships under clear skies confirm the relationships expressed in the manuscript.

Figure A4 shows a similar increasing depolarization increase rate to that in Fig. 6. This indicates that the increase depolarization ratio lapse rate does not come from clouds, Rayleigh scattering, or ozone absorption.

Since the CALIOP Level 1 product does not provide retrieved dust particulate depolarization ratio values, we examine near-cloud changes in dust particulate depolarization ratio values calculated using the following formula (e.g., Cairo et al, 1999; Liu et al, 2008; Omar et al, 2009)

$\delta_{\mathrm{p}}=\frac{\delta_{\mathrm{v}}\left[R+R \cdot \delta_{\mathrm{m}}-\delta_{\mathrm{m}}\right]-\delta_{\mathrm{m}}}{R-1+R \cdot \delta_{\mathrm{m}}-\delta_{\mathrm{v}}}$

where $\delta_{\mathrm{p}}, \delta_{\mathrm{v}}$ and $\delta_{\mathrm{m}}$ are the particulate depolarization ratio, volume depolarization ratio, and molecular depolarization ratio, while $R$ is the backscatter ratio determined by the particulate backscatter coefficient $\beta_{\mathrm{p}}$ and molecular backscatter coefficient $\beta_{\mathrm{m}}$ using $R=\left(\beta_{\mathrm{p}}+\beta_{\mathrm{m}}\right) / \beta_{\mathrm{m}}$.

The estimated dust particulate depolarization ratio in Fig. A5 shows qualitatively the same near cloud behavior as Fig. 7d. This confirms that the behavior in Fig. $7 d$ is not the result of Rayleigh scattering or ozone attenuation. 

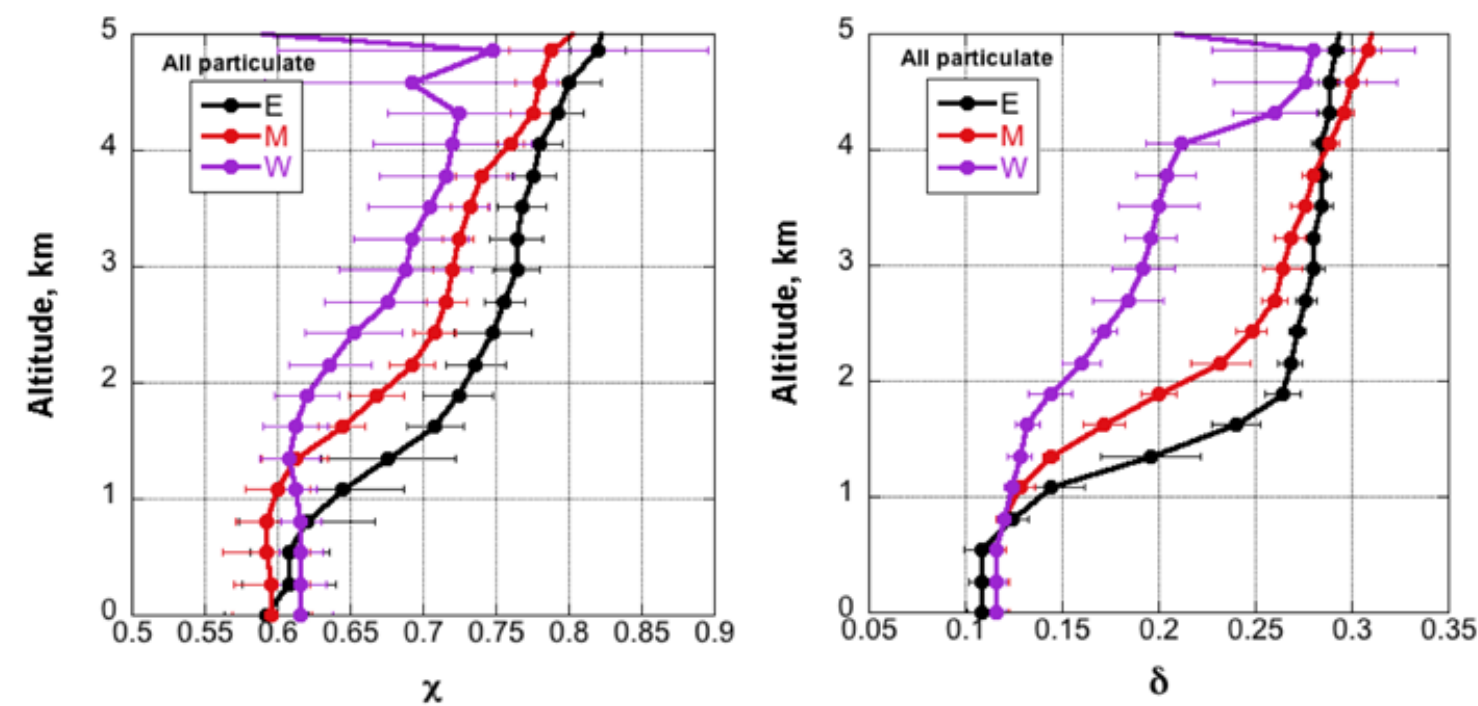

Fig. A1. Vertical distribution of retrieved dust particulate color ratio (left) and depolarization ratio (right). These plots correspond to Fig. 2b and d.
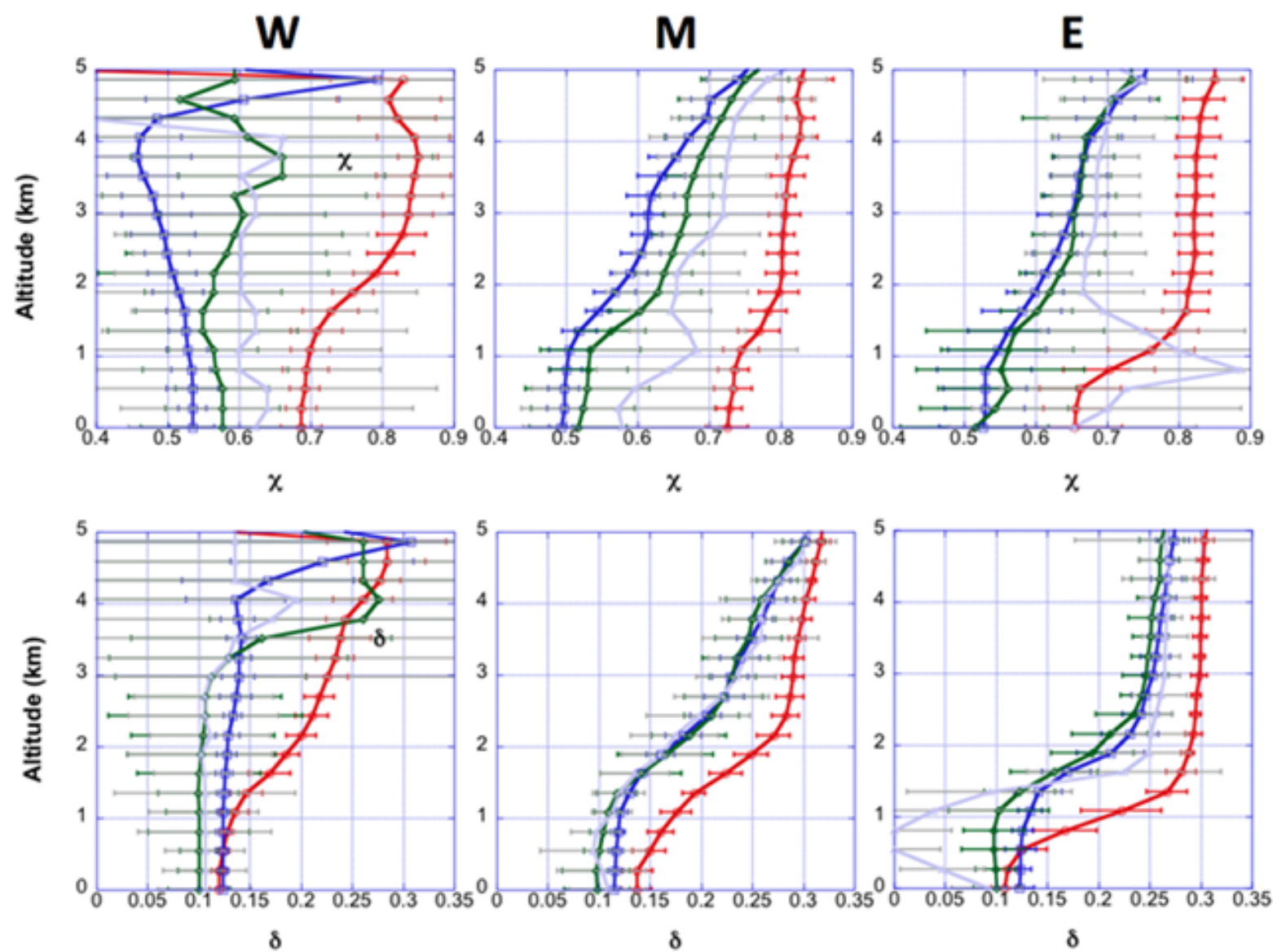

Fig. A2. Effect of cloud fraction on the vertical distribution of dust particulate color ratio (first row) and depolarization ratio (second row). These two rows correspond to the 3rd and 4th rows of Fig. 4. 

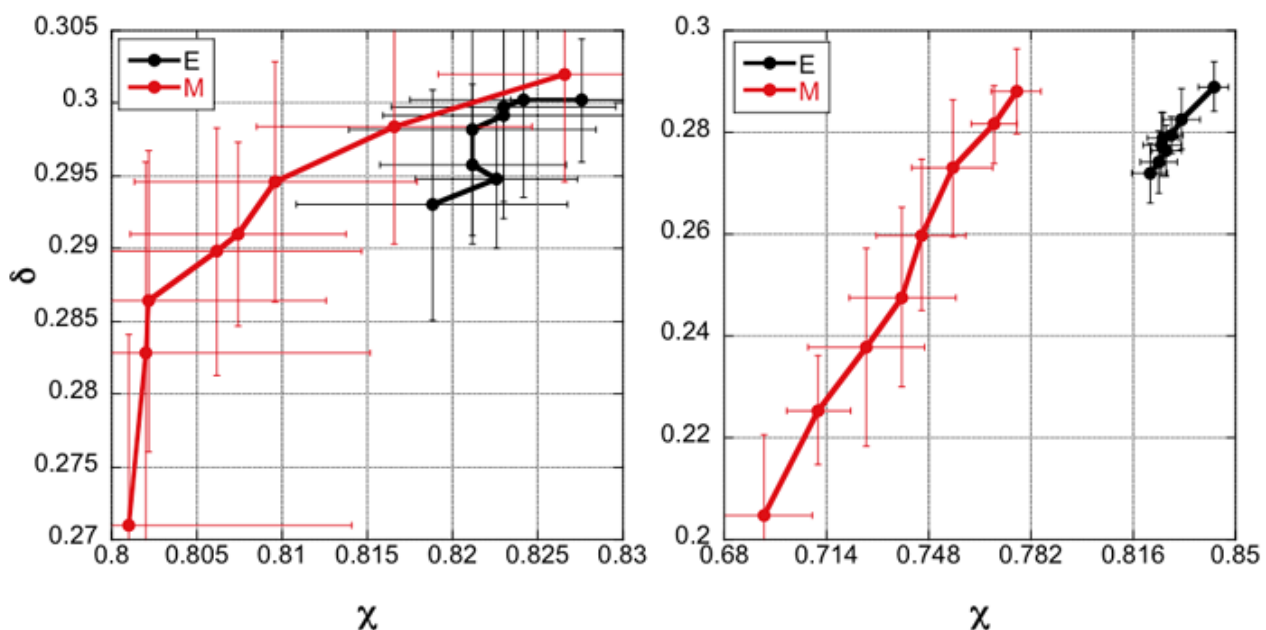

Fig. A3. Depolarization ratio as a function of color ratio, based on dust particulate properties. These panels correspond to Fig. 5a and b according from Left to Right.

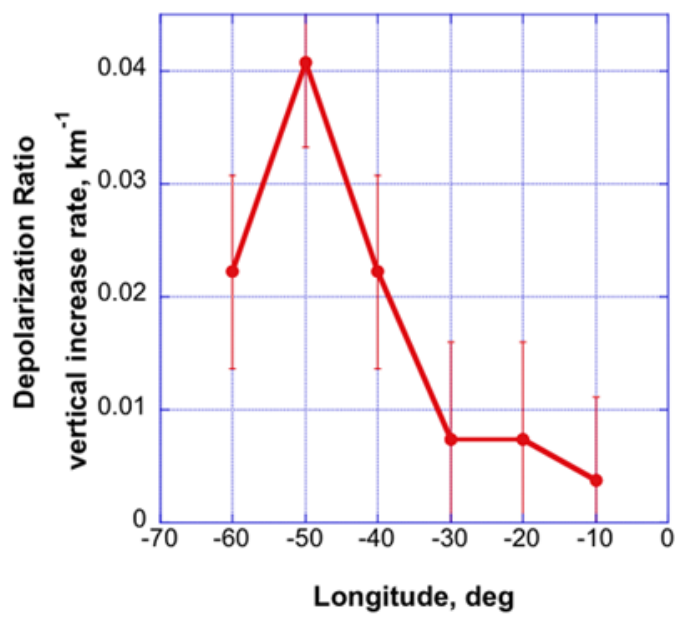

Fig. A4. Rate of vertical increase in dust particulate depolarization ratio between 3 and $4 \mathrm{~km}$ altitudes, vs. distance from the African coast. This corresponds to the Fig. 6 .

Acknowledgements. We gratefully acknowledge support for this research by the NASA Radiation Sciences Program managed by Hal Maring, and by the NASA CALIPSO project supervised by Charles Trepte as the technical officer. This work was supported, in part, by NSF-AGS-1119164. We also wish to give special thanks to Peter R. Colarco, Ralph A. Kahn, Robert C. Levy, Zhaoyan Liu, Yuekui Yang, Hongbin Yu, Tianle Yuan, and other scientists at NASA GSFC for their helpful suggestions and fruitful discussions.

Edited by: O. Möhler

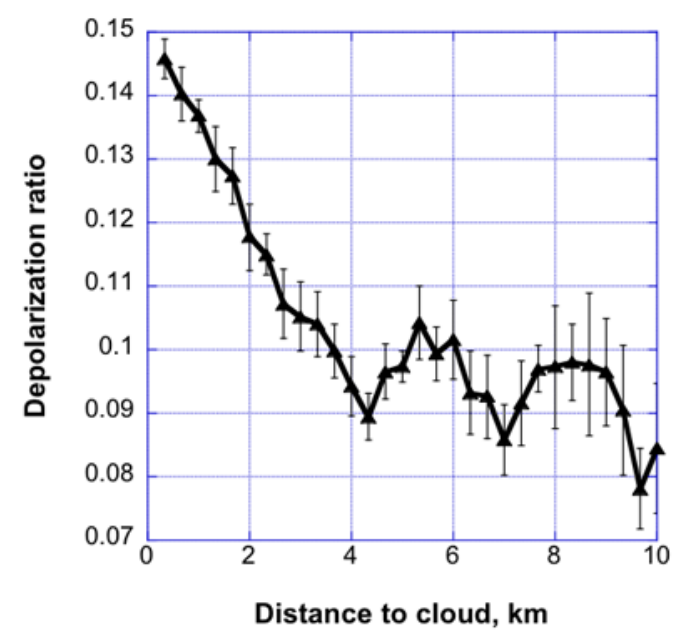

Fig. A5. Estimated particulate depolarization ratio as a function of distance to clouds for low dust. This panel corresponds to Fig. 7d.

\section{References}

Ansmann, A., Bösenberg, J., Chaikovsky, A., Comerón, A., Eckhardt, S., Eixmann, R., Freudenthaler, V., Ginoux, P., Komguem, L., Linné, H., López Márquez, M. A., Matthias, V., Mattis, I., Mitev, V.,Müller, D., Music, S., Nickovic, S., Pelon, J., Sauvage, L., Sobolewsky, P., Srivastava, M. K., Stohl, A., Torres, O., Vaughan, G.,Wandinger, U., and Wiegner, M.: Long-range transport of Saharan dust to northern Europe: The 11-16 October 2001 outbreak observed with EARLINET, J. Geophys. Res., 108, 4783, doi:10.1029/2003JD003757, 2003.

Ansmann, A., Tesche, M., Althausen, D., Mueller, D., Seifert, P., Freudenthaler, V., Heese, B., Wiegner, M., Pisani, G., Knippertz, P., and Dubovik, O.: Influence of Saharan dust on cloud glaciation in southern Morocco during the Saharan Mineral Dust Experiment, J. Geophys. Res., 113, D04210, 
doi:10.1029/2007JD008785, 2008.

Ansmann, A., Baars, H., Tesche, M., Müller, D., Althausen, D., Engelmann, R., Pauliquevis, T., and Artaxo, P.: Dust and smoke transport from Africa to South America: Lidar profiling over Cape Verde and the Amazon rainforest, Geophys. Res. Lett., 36, L11802, doi:10.1029/2009GL037923, 2009.

Ansmann, A., Petzold, A., Kandler, K., Tegen, I., Wendisch, M., Müller, D., Weinzierl, B., Müller, T., and Heintzenberg, J.: Saharan Mineral Dust Experiments SAMUM-1 and SAMUM-2: what have we learned?, Tellus, 63B, 403-429, 2011.

Bi, L., Yang, P., Kattawar, G. W., Baum, B. A., Hu, Y. X., Winker, D. M., Brock, R. S., and Lu, J. Q.: Simulation of the color ratio associated with the backscattering of radiation by ice particles at the wavelengths of 0.532 and $1.064 \mathrm{~mm}$, J. Geophys. Res., 114, D00H08, doi:10.1029/2009JD011759, 2009.

Cairo, F., Donfrancesco, G., Adriani, A., Pulvirenti, L., and Federico, F.: Comparison of various linear depolarization parameters measured by lidar, Appl. Opt., 38, 4425-4432, 1999.

Carlson, T. N. and Prospero, J. M.: The large-scale movement of Saharan air outbreaks over the northern equatorial Atlantic, J. Appl. Meteorol., 11, 283-297, 1972.

Cheng, Y.-S., Yeh, H.-C., and Allen, M. D.: Dynamic shape factor of a plate-like particle, Aerosol Sci. Technol., 8, 109-123, 1988.

Chou, C., Formenti, P., Maille, M., Ausset, P., Helas, G., Harrison, M., and Osborne, S.: Size distribution, shape, and composition of mineral dust aerosols collected during the African Monsoon multidisciplinary analysis special observation period 0: dust and biomass- burning experiment field campaign in Niger, January 2006, J. Geophys. Res., 113, D00C10, doi:10.1029/2008jd009897, 2008.

Clarke, A. D., Howell, S., Quinn, P. K., Bates, T. S., Ogren, J. A., Andrews, E., Jefferson, A., and Massling, A.: INDOEX aerosol: A comparison and summary of chemical, microphysical, and optical properties observed from land, ship, and aircraft, J. Geophys. Res., 107, D08033, doi:10.1029/2001JD000572, 2002.

Davidi, A., Kostinski, A. B., Koren, I., and Lehahn, Y.: Observational bounds on atmospheric heating by aerosol absorption: Radiative signature of transatlantic dust, Geophys. Res. Lett., 39, L04803, doi:10.1029/2011GL050358, 2012.

DeMott, P. J., Sassen, K., Poellot, M. R., Baumgardner, D., Rogers, D. C., Brooks, S. D., Prenni, A. J., and Kreidenweis, S. M.: African dust aerosols as atmospheric ice nuclei, Geophys. Res. Lett., 30, L1732, doi:10.1029/2003GL017410, 2003.

Dubovik, O., Sinyuk, A., Lapyonok, T., Holben, B. N., Mishchenko, M., Yang, P., Eck, T. F., Volten, H., Muñoz, O., Veihelmann, B., van der Zande, W. J., Leon, J. F., Sorokin, M., and Slutsker, I.: Application of spheroid models to account for aerosol particle nonsphericity in remote sensing of desert dust, J. Geophys. Res., 111, D11208, doi:10.1029/2005JD006619, 2006.

Efron, B. and Gong, G.: A leisurely look at the bootstrap, the jackknife, and cross-validation, The American Statistician, 37, 3648, 1983.

Freudenthaler, V., Esselborn, M., Wiegner, M., Heese, B., Tesche, M., Ansmann, A., Müller, D., Althausen, D., Wirth, M., Fix, A., Ehret, G., Knippertz, P., Toledano, C., Gasteiger, J., Garhammer, M., and Seefeldner, M.: Depolarization-ratio profiling at several wavelengths in pure Saharan dust during SAMUM 2006, Tellus B, 61, 165-179, 2009.
Ginoux, P.: Effects of nonsphericity on mineral dust modeling, J. Geophys. Res., 108, D04052, doi:10.1029/2002JD002516, 2003.

Heintzenberg, J.: The SAMUM-1 experiment over Southern Morocco: overview and introduction, Tellus B, 61, 2-11, doi:10.1111/j.1600-0889.2008.00403.x, 2009.

Huang, J., Zhang, C., and Prospero, J. M.: African dust outbreaks: A satellite perspective of temporal and spatial variability over the tropical Atlantic Ocean, J. Geophys. Res., 115, D05202, doi:10.1029/2009JD012516, 2010.

IPCC: Climate Change: The Scientific Basis, edited by: Houghton, J. T., Ding, Y., Griggs, D. J., Noguer, M., van der Linden, P. J., Dai, X., Maskell, K., and Johnson, C. A., Cambridge University Press, Cambridge, UK, 881 pp., 2001.

IPCC: Climate Change: The Physical Science Basis, edited by: Solomon, S., Qin, D., Manning, M., Chen, Z., Marquis, M., Avery, K. B., Tignor, M., and Miller, H. L., Cambridge University Press, Cambridge, United Kingdom and New York, NY, USA, 996 pp., 2007.

Johnson, D. B.: The role of giant and ultragiant aerosol particles in warm rain initiation, J. Atmos. Sci., 39, 448-460, doi:10.1175/1520-0469(1982)039;0448:TROGAU;2.0.CO;2, 1982.

Kaaden, N., Massling, A., Schladitz, A., Mueller, T., Kandler, K., Schuetz, L., Weinzierl, B., Petzold, A., Tesche, M., Leinert, S., Deutscher, C., Ebert, M., Weinbruch, S., and Wiedensohler, A.: State of mixing, shape factor, number size distribution, and hygroscopic growth of the Saharan anthropogenic and mineral dust aerosol at Tinfou, Morocco, Tellus B, 61, 51-63, 2009.

Kahnert, M., Nousiainen, T., and Raisanen, P.: Mie simulations as an error source in mineral aerosol radiative forcing calculations, Q. J. R. Meteorol. Soc., 133, 299-307, 2007.

Kalashnikova, O. V. and Kahn, R. A.: Mineral dust plume evolution over the Atlantic from MISR and MODIS aerosol retrievals, J. Geophys. Res., 113, D24204, doi:10.1029/2008JD010083, 2008.

Kalashnikova, O. V. and Sokolik, I. N.: Importance of shapes and compositions of wind-blown dust particles for remote sensing at solar wavelengths, Geophys. Res. Lett., 29, 1398, doi:10.1029/2002GL014947, 2002.

Kandler, K., Benker, N., Bundke, U., Cuevas, E., Ebert, M., Knippertz, P., Rodriguez, S., Schütz, L., and Weinbruch, S.: Chemical composition and complex refractive index of Saharan mineral dust at Izana, Tenerife (Spain) derived by electron microscopy, Atmos. Environ., 41, 8058-8074, 2007.

Kandler, K., Schütz, L., Deutscher, C., Ebert, M., Hofmann, H., Jäckel, S., Jaenicke, R., Knip- pertz, P., Lieke, K., Massling, A., Petzold, A., Schladitz, A., Weinzierl, B., Wiedensohler, A., Zorn, S., and Weinbruch, S.: Size distribution, mass concentration, chemical and mineralogical composition and derived optical parameters of the boundary layer aerosol at Tinfou, Morocco, during SAMUM 2006, Tellus B, 61, 32-50, doi:10.1111/j.16000889.2008.00385.x, 2009.

Kaufman, Y. J., Koren, I., Remer, L. A., Tanré, D., Ginoux, P., and Fan, S.: Dust transport and deposition observed from the Terra- Moderate Resolution Imaging Spectroradiometer (MODIS) spacecraft over the Atlantic Ocean, J. Geophys. Res., 110, D10S12, doi:10.1029/2003JD004436, 2005.

Kelly, J. T., Chuang, C. C., and Wexlerm, A. S.: Influence of dust composition on cloud droplet formation, Atmos. Environ., 41, 2904-2916, 2007. 
Koren, I., Remer, L. A., Kaufman, Y. J., Rudich, Y., and Martins, J. V.: On the twilight zone between clouds and aerosols, Geophys. Res. Lett., 34, L08805, doi:10.1029/2007GL029253, 2007.

Lafon, S., Sokolik, I. N., Rajot, J. L., Caquineau, S., and Gaudichet, A.: Characterization of iron oxides in mineral dust aerosols: implications for light absorption, J. Geophys. Res., 111, D21207, doi:10.1029/2005jd007016, 2006.

Levin, Z., Ganor, E., and Gladstein, V.: The effects of desert particles with sulfate on rain formation in the eastern Mediterranean, J. Appl. Meteorol., 35, 1511-1523, 1996.

Li-Jones, X., Maring, H. B., and Prospero, J. M.: Effect of relative humidity on light scattering by mineral dust aerosol as measured in the marine boundary layer over the tropical Atlantic Ocean, J. Geophys. Res., 103, 31113-31121, doi:10.1029/98JD01800, 1998.

Liu, Z., Vaughan, M., Winker, D., Hostetler, C. A., Poole, L. R., Hlavka, D. L., Hart, W. D., and McGill, M. J.: Use of probability distribution functions for discriminating between cloud and aerosol in lidar backscatter data, J. Geophys. Res., 109, D15202, doi:10.1029/2004JD004732, 2004.

Liu, Z., Omar, A., Vaughan, M., Hair, J., Kittaka, C., Hu, Y., Powell, K., Trepte, C., Winker, D., Hostetler, C., Ferrare, R., and Pierce, R.: CALIPSO lidar observations of the optical properties of Saharan dust: A case study of long-range transport, J. Geophys. Res., 113, D07207, doi:10.1029/2007JD008878, 2008.

Liu, Z., Vaughan, M. A., Winker, D. M., Kittaka, C., Kuehn, R. E., Getzewich, B. J., Trepte, C. R., and Hostetler, C. A.: The CALIPSO Lidar Cloud and Aerosol Discrimination: Version 2 Algorithm and Initial Assessment of Performance, J. Atmos. Oceanic Technol., 26, 1198-1213, doi:10.1175/2009JTECHA1229.1, 2009.

Lohmann, U. and Feichter, J.: Global indirect aerosol effects: a review, Atmos. Chem. Phys., 5, 715-737, doi:10.5194/acp-5-7152005, 2005.

Marshak, A., Wen, G., Coakley Jr., J. A., Remer, L. A., Loeb, N. G., and Cahalan, R. F.: A simple model for the cloud adjacency effect and the apparent bluing of aerosols near clouds, J. Geophys. Res., 113, D14S17, doi:10.1029/2007JD009196, 2008.

Mattsson, J. O. and Nihlen, T.: The transport of Saharan dust to southern Europe: A scenario, J. Arid Environ., 32, 111-119, doi:10.1006/jare.1996.0011, 1996.

Murayama, T., Sugimoto, N., Uno, I., Kinoshita, K., Aoki, K., Hagiwara, N., Zhaoyan Liu, Matsui, I., Sakai, T., Shibata, T., Arao, K., Sohn, B.J., Won, J.G., Yoon, S.C., Li, T., Zhou, J., Hu, H.L., Abo, M., Iokibe, K., Koga, R. and Iwasaka, Y.: Ground-based network observation of Asian dust events of April 1998 in east Asia, J. Geophys. Res., 106, 18346-18359, 2001.

Nousiainen, T.: Optical modeling of mineral dust particles: A review, J. Quant. Spectrosc. Ra., 110, 1261-1279, 2009.

Omar, A. H., Winker, D., Kittaka, C., Vaughan, M., Liu, Z., Hu, Y., Trepte, C., Rogers, R., Ferrare, R., Lee, K.-P., Kuehn, R., and Hostetler, C.: The CALIPSO Automated Aerosol Classification and Lidar Ratio Selection Algorithm, J. Atmos. Oceanic Technol., 26, 1994-2014. doi:10.1175/2009JTECHA1231.1, 2009.

Osborne, S. R., Johnson, B. T., Haywood, J. M., Baran, A. J., Harrison, M. A. J., and Mc-Connell, C. L.: Physical and optical properties of mineral dust aerosol during the dust and biomass-burning experiment, J. Geophys. Res., 113, D00C03, doi:10.1029/2007JD009551, 2008.
Petzold, A., Rasp, K., Weinzierl, B., Esselborn, M., Hamburger, T., Dörnbrack, A., Kandler, K., Schütz, L., Knippertz, P., Fiebig, M., and Virkkula, A.: Saharan dust absorption and refractive index from aircraft-based observations during SAMUM 2006, Tellus B, 61, 118-130, doi:10.1111/j.1600-0889.2008.00383.x, 2009.

Prospero, J. M. and Carlson, T. N.: Vertical and areal distribution of Saharan dust over the western equatorial North Atlantic ocean, J. Geophys. Res., 77, 5255-5265, 1972.

Prospero, J. M. and Lamb, P. J.: African droughts and dust transport to the Caribbean: Climate change implications, Science, 302, 1024-1027, 2003.

Reid, J. and Maring, H.: Foreword to special section on the Puerto Rico Dust Experiment (PRIDE), J. Geophys. Res.-Atmos., 108, 8585, doi:10.1029/2003JD003510, 2003.

Redelsperger, J.-L., Thorncroft, C. D., Diedhiou, A., Lebel, T., Parker, D. J., and Polcher, J.: African monsoon multidisciplinary analysis: an international research project and field cam 25 paign, B. Am. Meteorol. Soc., 87, 1739-1746, doi:10.1175/BAMS-8712-1739, 2006.

Redemann, J., Zhang, Q., Russell, P. B., Livingston, J. M., and Remer, L. A.: Case Studies of Aerosol Remote Sensing in the Vicinity of Clouds, J. Geophys. Res., 114, D06209, doi:10.1029/2008JD010774, 2009.

Sassen, K.: The lidar backscatter depolarization technique for cloud and aerosol research, in: Light Scattering by Nonspherical Particles: Theory, Measurements, and Geophysical Applications, edited by: Mishchenko, M. L., Hovenier, J. W., and Travis, L. D., Academic, San Diego, California, 393-416, 2000.

Sassen, K., De Mott, P. J., Prospero, J. M., and Poellot, M. R.: Saharan dust storms and indirect aerosol effects on clouds: CRYSTAL-FACE results, Geophys. Res. Lett., 30, 1633, doi:10.1029/2003GL017371, 2003.

Schladitz, A., Müller, T., Nowak, A., Kandler, K., Lieke, K., Massling, A. and Wiedensohler,A.: In situ aerosol characterization at Cape Verde, part 1: particle number size distributions, hygroscopic growth, and state of mixing of the marine and Saharan dust aerosol, Tellus B, 63, 531-548, 2011.

Sokolik, I. and Toon, O.: Incorporation of mineralogical composition into models of the radiative properties of mineral aerosol from UV to IR wavelengths, J. Geophys. Res., 104, 9423-9444, 1999.

Su, W., Schuster, G. L., Loeb, N. G., Rogers, R. R., Ferrare, R. A., Hostetler, C. A., Hair, J. W., and Obland, M. D.: Aerosol and cloud interaction observed from high spectral resolution lidar data, J. Geophys. Res., 113, D24202, doi:10.1029/2008JD010588, 2008.

Tanré, D., Haywood, J., Pelon, J., Le'on, J. F., Chatenet, B., Formenti, P., Francis, P., Goloub, P., Highwood, E. J., and Myhre, G.: Measurement and modeling of the Saharan dust radiative impact: overview of the Saharan Dust Experiment (SHADE), J. Geophys. Res., 108, 8574, doi:10.1029/2002jd003273, 2003.

Tackett, J. L. and Girolamo, L. D.: Enhanced aerosol backscatter adjacent to tropical trade wind clouds revealed by satellite-based lidar, Geophys. Res. Lett., 36, L14804, doi:10.1029/2009GL039264, 2009.

Tesche, M., Ansmann, A., Müuller, D., Althausen, D., Mattis, I., Heese, B., Freudenthaler, V., Wiegner, M., Eseelborn, M., Pisani, G., and Knippertz, P.: Vertical profiling of Saharan dust with Raman lidars and airborne HSRL in Southern Morocco 
during SAMUM, Tellus B, 61, 144-164, doi:10.1111/j.16000889.2008.00390.x, 2009.

Tesche, M., Groß, S., Ansmann, A., Müuller, D., Althausen, D., Freudenthaler, V., and Esselborn, M.: Profiling of Saharan dust and biomass-burning smoke with multiwavelength polarization Raman lidar at Cape Verde, Tellus B, 63, 649-676, doi:10.1111/j.1600-0889.2011.00548.x, 2011.

Torres, O., Bhartia, P. K., Herman, J. R., Sinyuk, A., Ginoux, P., and Holben, B.: A long-term record of aerosol optical depth from TOMS observations and comparison to AERONET measurements, J. Atmos. Sci., 59, 398-413, 2002.

Twomey, S.: Atmospheric Aerosols, Elsevier North-Holland Inc. 52, Vanderbilt Avenue, New York, New York, 10017, 203 pp., 1977.

Twohy, C. H., Clement, C. F., Gandrud, B. W., Weinheimer, A. J., Campos, T. L. Baumgardner, D., Brune, W. H., Faloona, I., Sachse, G. W., Vay, S. A., and Tan, D.: Deep convection as a source of new particles in the midlatitude upper troposphere, J. Geophys. Res., 107, 4560, doi:10.1029/2001JD000323, 2002.

Twohy, C. H., Kreidenweis, S. M., Eidhammer, T., Browell, E. V., Heymsfield, A. J., Bansemer, A. R., Anderson, B. A., Chen, G., Ismail, S., DeMott, P. J., and Van Den Heever, S. C.: Saharan dust particles nucleate droplets in eastern Atlantic clouds, Geophys. Res. Lett., 36, L01807, doi:10.1029/2008GL035846, 2009a.

Twohy, C. H., Coakley Jr., J. A., and Tahnk, W. R.: Effect of changes in relative humidity on aerosol scattering near clouds, J. Geophys. Res., 114, D05205, doi:10.1029/2008JD010991, 2009b.

Várnai, T. and Marshak, A.: Global CALIPSO observations of aerosol changes near Clouds, IEEE Rem. Sens. Lett., 8, 19-23, 2011.

Várnai, T. and Marshak, A.: Analysis of co-located MODIS and CALIPSO observations near clouds, Atmos. Meas. Tech., 5, 389-396, doi:10.5194/amt-5-389-2012, 2012.

Vaughan, M. A., Young, S., Winker, D., Powell, K., Omar, A., Liu, Z., Hu, Y., and Hostetler, C.: Fully automated analysis of spacebased lidar data: An overview of the CALIPSO retrieval algorithms and data products, Laser Radar Techniques for Atmospheric Sensing, edited by: Upendra, N., Singh, Proceedings of SPIE, 5575, 16-30, 2004.
Vaughan, M., Powell, K., Kuehn, R., Young, S., Winker, D., Hostetler, C., Hunt, W., Liu, Z., McGill, M., and Getzewich, B.: Fully Automated Detection of Cloud and Aerosol Layers in the CALIPSO Lidar Measurements, J. Atmos. Oceanic Technol., 26, 2034-2050, doi:10.1175/2009JTECHA1228.1, 2009.

Wang, J., Flagan, R. C., Seinfeld, J. H., Jonsson, H. H., Collins, D. R., Russell, P. B., Schmid, B., Redemann, J., Livingston, J. M., Gao, S., Hegg, D. A., Welton, E. J., and Bates, D.: Clearcolumn radiative closure during ACE-Asia: comparison of multiwavelength extinction derived from particle size and composition with results from Sun photometry, J. Geophys. Res., 107, 4688, doi:10.1029/2002JD002465, 2002.

Wen, G., Marshak, A. Cahalan, R. F., Remer, L. A., and Kleidman, R. G.: 3-D aerosol-cloud radiative interaction observed in collocated MODIS and ASTER images of cumulus cloud fields, J. Geophys. Res., 112, D13204, doi:10.1029/2006JD008267, 2007.

Winker, D. M., Pelon, J. R., and McCormick, M. P.: The CALIPSO mission: spaceborne lidar for observation of aerosols and clouds, Proc. Spie., 1, 4893, doi:10.1117/12.466539, 2003.

Winker, D. M., Vaughan, M. A., Omar, A., Hu, Y., Powell, K. A., Liu, Z., Hunt, W. H., and Young, S. A.: Overview of the CALIPSO Mission and CALIOP Data Processing Algorithms, J. Atmos. Oceanic Technol., 26, 2310-2323, doi:10.1175/2009JTECHA1281.1, 2009.

Wurzler, S., Reisin, T. G., and Levin, Z.: Modification of mineral dust particles by cloud processing and subsequent effects on drop size distributions, J. Geophys. Res., 105, 4501-4512, doi:10.1029/1999JD900980, 2000.

Yin, Y., Wurzler, S., Levin, Z., and Reisin, T. G.: Interactions of mineral dust particles and clouds: Effects on precipitation and cloud optical properties, J. Geophys. Res., 107, 4724, doi:10.1029/2001JD001544, 2002. 